THURSDAY, APRIL I8, Igi8.

\section{A MINISTRY OF HEALTH.}

STUDENTS of public health have long been aware of the fact that the application to the general community of the methods of preventing and curing disease is seriously incommensurate with our knowledge of these methods. Tuberculosis we believe to be an almost, if not entirely, preventable disease, yet it is still the largest single cause of death; rickets, probably an exclusively environmental disorder, produces defects and deformities persisting through life in a large proportion of the poorer classes; infant mortality is probably exactly double what it would be if we could place every infant in a healthy environment; Sir George Newman has told us that a million school children suffer from physical or mental deficiencies, which render attempts to educate them almost useless, yet here also the physique and healthiness of the average public-school boy prove once more that the elementary-school child is the victim of pernicious surroundings.

When we turn to curative measures we find that the refinements of modern medicine, the skill of the specialist, the use of instruments of precision, and the scientific methods of diagnosis are, to a large extent, only available to the masses through the hospitals, and though these institutions are rendering services of the utmost value to the nation, they are very far from being able to meet the demand for their help owing to their limited accommodation.

The relative inefficiency of the public health and medical services in this country has been to a considerable extent concealed by the fact that since the middle of last century there has been a great decline in disease and a considerable fall in the death-rate. This improvement followed the work of Chadwick, Southwood Smith, Farr, Simon, and other pioneers of modern sanitation, and synchronised with the steady advance in the methods of disposal of sewage, removal of refuse, and provision of pure drinking water. It is no disparage. ment to these great names to say that modern scientific opinion tends to attribute to natural causes a larger share in the disappearance or diminution of diseases than a previous generation or even the unirstructed public of to-day would be prepared to allow. The remarkable decline in typhoid we owe almost certainly to sanitary effort. but biological influences, not yet fully understood, probably led to the disappearance of typhus, while a process of natural immunisation seems to have had at least as much to do with the decline of

$$
\text { NO. } 2529 \text {, VOL. IOI] }
$$

tuberculosis as improvements in environment and food-supply. The object of these remarks is to point out that, while we should not belittle the achievements of the past, there is distinct danger of attributing too much to our efforts and of surveying our labours with unmerited complacency. Certainly at the present day there is much in our public health administration which calls for censure rather than for praise.

In these circumstances the proposal to form a Ministry of Health is highly satisfactory, and if Dr. Addison, Lord Rhondda, and others concerned with or interested in the Bill take full advantage of their opportunities they can produce a measure of great social value. The important thing is to see that we are not satisfied with mere names or with a simple rearrangement of existing authorities, but that the scope of public health administration is widened, and that we get to grips with the bedrock causes of disease and with the means of their prevention and cure. So far as is generally known at present, the main object of the Bill is to unite or co-ordinate existing authorities, and we have heard of prolonged negotiations as to whether the Insurance Commissioners, the Local Government Board, or an entirely new body is to form the Ministry. Increased co-operation between the central administrative authorities will be all to the good, for there is no doubt that their present relative isolation leads to much delay, confusion, and unnecessary expense ; but we must not suppose that departmental reorganisation, desirable though it is, will have much effect by itself in improving public health. The history of public health legislation in this country shows that two important principles should be observed if the mistakes of the past are to be avoided.

The first principle is to maintain and extend scientific research in all branches of medicine and public health. This at once raises the question of what is to be the position of the Research Committee in regard to the new Ministry. It is not yet known whether the Committee is to form part of the Ministry, but it is generally understood that the Bill immediately to be introduced is of comparatively limited scope and provides for the gradual absorption of various departments as may be found expedient. We would earnestly plead that the Research Committee should be left either entirely outside the Ministry, or, if united to it, should be practically independent and uncontrolled by any administrative branch of the Ministry. Scientific research, to be of any value, must be unfettered. Moreover, the Research Committee must have the right to investigate the results of measures taken by any branch of the Ministry and 
to indicate where these measures have failed to achieve their object. At the present time there is more than a tendency in many of the reports issued by Government departments responsible for public health administration to give an unduly favourable picture of the results of their work.

Another function of the research department of the Ministry should be to examine critically all proposed public health legislation. Too often have purely popular views of the causation and prevention of disease formed the basis of public health Acts, and often these views have had little scientific foundation, with the result that much time has been wasted and money uselessly spent. It is too much to hope that the Minister of Public Health will always be a member of the medical profession, but at least we may hope that the political Minister will be assisted by a professional director at the head of the administration, with an expert committee of the highest standing, and that future public health Bills will be presented to Parliament only after they have been thoroughly examined and criticised by this committee. Thus only shall we avoid repeating the failures which have been so conspicuous in recent public health legislation.

The second principle is concerned with the relation of the Ministry to local public health authorities. Here we may be anticipating, for no hint has yet been given that the local authorities are to be touched by the Bill. Yet the limitation of reform to the central authorities (if it is to be so) must be quite temporary, for without reorganisation of the local bodies which are administering public health measures the value of the Bill will be very small. It is, indeed, arguable that the start should have been made with the local authorities, leaving the reorganisation of the central departments for later consideration. A complete and really effective scheme, however, demands the co-ordination of the local sanitary authority, the insurance committee, the board of guardians, the pensions committee, and other authorities which are engaged in some form or other with public health and medical services. At present the overlapping and independent working of these bodies is productive of more confusion and delay and constitutes a greater evil than the lack of co-ordination among the central authorities. Probably the best plan would be to replace or unite all these bodies in one local authority, which in county boroughs would be the borough council, and in counties the county council, exercising some of its powers through the urban and rural district councils. The creation of entirely new local public health authorities has also been advocated.

$$
\text { NO. 2529, VOL. IOI] }
$$

Closely associated with this question is the proper division of power between the central and local authorities. Here, as in so many other social activities, two schools of opinion exist: one which advocates increased central control, mainly for the reason that it considers local control unsatisfactory and desires to subject the authorities to a process of "gingering up "; while the other is in favour of a large measure of decentralisation which would give local authorities increased powers at the expense of the central departments. The holding of the balance fairly between these views demands nice judgment, but in our opinion a grear deal is to be said for decentralisation. In the first place, the larger local authorities, as, for instance, the councils of the great towns, now display a sense of responsibility for their duties and a keenness in providing healthy conditions within their area which fully justify confidence being placed in them. Indeed, the complaint is often heard that the obligation local authorities may be under to submit their proposals to a central body for approval is a serious cause of delay and inefficiency. Secondly, the local incidence of disease and the causes of disease vary so widely from place to place that a large element of elasticity in the preventive measures is necessary if appropriate remedial steps are to be taken. Centralisation of authority tends towards an undesirable uniformity over the whole country. If, on the other hand, local authorities can act on their own initiative they are in a position to establish just those systems of prevention and forms of treatment which the local circumstances demand.

The proposal to form a Ministry of Health was first made many years ago, but it has required the stimulus of a great war to bring it into being. The difficulties before the Ministry-at any time great -are now all the greater in the circumstances in which it begins its task. The supreme fact is that the introduction of this Bill definitely marks the assumption of responsibility by Government for the health of the people, and as such it will be welcomed by all who have the nation's well-being at heart.

\section{ALCOHOL, ITS USE AND ABUSE.}

Alcohol: Its Action on the Human Organism. Pp. xii $+\mathrm{r} 33+$ Appendix and Index x. (London : H.M.S.O., I918.) Price 2s. 6d. net.

THE form of this little volume is a welcome innovation in Government reports, attracting, instead of repelling, the reader. Its object is to present the conclusions arrived at by a committee of the Liquor Control Board after a cold and dispassionate examination of the effects of alcohol. No statements are made without exact 